\title{
A TRANSVERSALIDADE DAS REGULAÇÕES EM EDUCAÇÃO: MODELO DE ANÁLISE PARA O ESTUDO DAS POLÍTICAS EDUCATIVAS EM PORTUGAL*
}

\author{
JoÁo Barroso ${ }^{1}$ (D)
}

\begin{abstract}
RESUMO: No presente artigo, com base na investigação realizada ao longo destes anos, irei apresentar, num primeiro momento, uma síntese sobre a evolução recente dos processos de governança em educação nos países da Organização para a Cooperação e Desenvolvimento Económico (OCDE); num segundo momento, utilizarei alguns exemplos que ilustram a influência transnacional, nacional, municipal e da escola na produção de políticas educativas específicas em Portugal; finalmente, fundamentarei, a partir dos exemplos utilizados, a necessidade de ter em conta, na análise das políticas educativas, a transversalidade das regulaçóes e a interaçáo entre os diferentes níveis de influência.
\end{abstract}

Palavras-chave: Autonomia. Descentralização. Multirregulação. Regulação.

\section{THE TRANSVERSALITY OF REGULATIONS IN EDUCATION: A MODEL OF ANALYSIS FOR THE STUDY OF EDUCATIONAL POLICIES IN PORTUGaL}

ABSTRACT: Based on the research I have carried out over the years, in this paper, I will firstly present a synthesis on the recent evolution of governance processes in education in OECD countries; secondly, I will present some examples of the influence of transnational, national, municipal agencies and schools on the production of specific educational policies in Portugal. Finally, from the examples previously used, I will justify the need to take into account the transversality of the regulations and the interaction between the different levels of influence for an education policy analysis.

Keywords: Autonomy. Decentralization. Multiregulation. Regulation.

\footnotetext{
*O presente artigo baseia-se na investigação que tenho realizado nos últimos anos no Instituto de Educação da Universidade de Lisboa nomeadamente no âmbito do projeto Knowandpol - The role of knowledge in the construction and regulation of health and education policy in Europe: convergences and specificities among nations and sectors, financiado pela União Europeia no âmbito do "Sixth Framework Programme Research, Technological Development and Demonstration - Priority 7 - Citizens and governance in a knowledge based society".

${ }^{1}$ Universidade de Lisboa - Lisboa, Portugal. E-mail: jbarroso@ie.ul.pt

DOI: 10.1590/ES0101-73302018214219
} 


\title{
LA TRANSVERSALITÉ DES RÉGULATIONS EN ÉDUCATION : MODÈLE D'ANALYSE POUR L'ÉTUde DES POLITIQUeS ÉdUCATIVES AU PORTUGal
}

\begin{abstract}
$R E S U M E ́$ : Dans cet article, appuyé dans la recherche que j’ai menée sur ce sujet, j’irai présenter, dans un premier moment, une synthèse sur l'évolution récente de la gouvernance en éducation dans les pays de l'Organisation pour la Coopération et le Développement Économique $(\mathrm{OCDE})$; dans un deuxième moment, j'utiliserai quelques exemples pour illustrer l'influence transnationale, nationale, municipale et de l'établissement scolaire dans la production des politiques éducatives au Portugal ; enfin, j’irai défendre le besoin de prendre en compte, dans l'analyse des politiques éducatives, la transversalité des régulations et l'interaction entre les différents niveaux d'influence.
\end{abstract}

Mots-clés : Autonomie. Décentralisation. Multirrégulation. Régulation.

\section{Introdução}

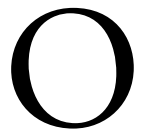

estudo sobre a regulação das políticas e da ação pública no domínio educativo, em Portugal, realizou-se, pela primeira vez, de uma forma sistemática, no âmbito de dois projetos europeus de investigação, por meio da pesquisa efetuada por duas equipas da Faculdade de Psicologia e de Ciências da Educação (atual Instituto de Educação), da Universidade de Lisboa, que coordenei.

O primeiro projeto intitulava-se Reguleducnetwork - Changes in regulation modes and social production of inequalities in educational systems: a European comparison ${ }^{1}$. Esse projeto teve início em outubro de 2001 e terminou em outubro de 2004, tendo integrado equipas de cinco países europeus: Bélgica (só a comunidade francesa), França, Hungria, Portugal e Reino Unido (só a Inglaterra e País de Gales). Foi subsidiado pela Comissão Europeia, no âmbito do programa "Improving the socio-economic knowledge Base" (Contrato no HPSE-CT-2001-00086). Em 2006, foi editada por mim, em colaboração com Sofia Viseu (BARROSO, 2006b), uma obra em que, para além de uma reflexão teórica sobre o quadro conceptual do projeto, eram apresentados diversos textos com a síntese dos principais resultados obtidos ${ }^{2}$. Na revista Educaçấo e Sociedade tive a oportunidade de editar três textos sobre este projeto: o primeiro no $\mathrm{n}^{\circ} 82$, em abril de 2003, inserido num dossiê sobre políticas educativas em Portugal e no Brasil (BARROSO, 2003); o segundo, em colaboração com Sofia Viseu, no no 84, igualmente em 2003, sobre o planeamento da rede escolar (BARROSO \& VISEU, 2003); e o terceiro, em 2005, no no 92, no qual tratava da regulação e da relaçáo entre o Estado e a educação (BARROSO, 2005). 
O segundo projeto intitulava-se Knowandpol - The role of knowledge in the construction and regulation of health and education policy in Europe: convergences and specificities among nations and sectors. Esse projeto teve início em outubro de 2006 e terminou em dezembro de 2011, tendo integrado 12 equipas de investigação de 8 países (Alemanha, Bélgica, França, Hungria, Noruega, Portugal, Reino Unido e Roménia), distribuídas pelos sectores da saúde e da educação. Foi um projeto financiado pela União Europeia no âmbito do "Sixth Framework Programme Research, Technological Development and Demonstration - Priority $7-\mathrm{Ci}$ tizens and governance in a knowledge based society"3. Em 2011, foram editadas duas obras que apresentam os principais resultados obtidos pela equipa portuguesa (BARROSO \& AFONSO, 2011; CARVALHO, 2011). Em 2009, organizei um dossier sobre a relação entre conhecimento e política para o no 209 da revista Educação e Sociedade, que incluiu artigos sobre temas tratados neste projeto da autoria de Delvaux (2009), de Barroso (2009), de Carvalho (2009) e de Costa e Afonso (2009).

A participação nesses dois projetos europeus deu lugar ao desenvolvimento de uma linha de pesquisa específica no Instituto de Educação da Universidade de Lisboa (antiga Faculdade de Psicologia e de Ciências da Educação da mesma universidade) sobre a regulação da ação pública e a fabricação de instrumentos baseados no conhecimento ${ }^{4}$. Essa linha de pesquisa tornou-se, igualmente, no tema central dos cursos de doutoramento em Administração e Politica Educacional dessa instituição, tendo sido elaboradas diversas teses que abordavam essa temática.

Eu próprio tenho vindo a desenvolver trabalhos sobre a regulação das políticas educativas, na continuidade dos estudos sobre a descentralização e o reforço da autonomia da escola (ver BARROSO, 2013, 2014, 2017, 2018, entre outros).

No presente artigo, com base na investigação realizada ao longo destes anos, irei apresentar, num primeiro momento, uma síntese sobre a evolução recente dos processos de governança em educação nos países da Organização para a Cooperação e Desenvolvimento Económico (OCDE); num segundo momento, utilizarei alguns exemplos que ilustram a influência transnacional, nacional, municipal e da escola na produção de políticas educativas específicas em Portugal; finalmente, fundamentarei, a partir dos exemplos utilizados, a necessidade de ter em conta, na análise das políticas educativas, a transversalidade das regulaçóes e a interação entre os diferentes níveis de influência.

\section{A governança dos sistemas de ensino}

A influência dos diferentes níveis de administração na governança ${ }^{5}$ dos sistemas de ensino tem evoluído nos últimos tempos, nomeadamente com o reforço da descentralização administrativa e da autonomia dos estabelecimentos de ensino. Contudo, como alerta um documento recente publicado pela OCDE 
(2017), a partir de informação recolhida quando da aplicação do Programme for International Student Assessment (PISA) de 2015, a complexidade crescente dos sistemas de ensino faz com que a delegação de poderes não possa ser vista de maneira linear, sem ter em conta a interdependência entre os diversos atores e as redes em que se situam. Como se afirma nesse documento (OCDE, 2017, p. 119), não basta determinar a delegação do poder para as autoridades locais para melhorar o funcionamento do sistema. É preciso conceder uma atenção especial às conexões e à interatividade, uma vez que elas podem gerar efeitos positivos ou negativos em diferentes partes do sistema. As soluçóes simples para problemas complexos estão condenadas ao fracasso. Por isso, a governança pública deve permanecer suficientemente flexível, adaptando-se ao dinamismo e à complexidade do sistema e prosseguindo os objetivos estabelecidos, dentro de um orçamento limitado. Nesse sentido, o documento a que temos vindo a fazer referência afirma que uma governança moderna e eficaz em matéria de educação apresenta as características seguintes:

Concentra-se nos processos e não nas estruturas. [...] - É flexível e capaz de se adaptar à mudança e a acontecimentos imprevistos. [...] - Apoia-se no reforço das suas capacidades, na implicação das partes e num diálogo aberto. [...] - Requer uma abordagem global à escala do sistema. [...] — Tira partido de dados probatórios e de trabalhos de investigação com o fim de sustentar a aplicaçáo das políticas e das reformas (OCDE, 2017, p. 119).

De acordo com o mesmo relatório, verifica-se, em muitos sistemas de ensino (Austrália, Canadá, Espanha, Finlândia, Hong Kong - China, Israel, Reino Unido, Singapura e Suécia, por exemplo), um aumento das responsabilidades dos estabelecimentos de ensino na tomada de decisão sobre os programas escolares e a afetação de recursos.

Esta gestáo à escala dos estabelecimentos de ensino torna necessário aumentar a responsabilidade dos diretores e, em certos casos, as responsabilidades dos professores ou dos diretores de departamento em matérias de gestão (OCDE, 2017, p. 120).

$\mathrm{O}$ aumento da responsabilidade dos estabelecimentos de ensino, em particular dos diretores, foi identificado no relatório que temos estado a seguir:

Em média, nos países da OCDE, a definição do salário inicial dos professores e dos aumentos posteriores releva principalmente da responsabilidade das autoridades nacionais enquanto a definição do conteúdo pedagógico dos diversos cursos e a escolha dos manuais escolares releva da responsabilidade dos professores. As políticas em matéria de avaliação e a disciplina são estabelecidas conjuntamente pela direçáo da escola e pelos professores. Todas as outras responsabilidades incumbem principalmente 
aos diretores, incluindo o recrutamento e o despedimento dos professores, a supervisão das questôes orçamentais, a definição das políticas em matéria de admissão de alunos e a definição dos cursos propostos pela escola (OCDE, 2017, p. 123).

$\mathrm{Na}$ tentativa de aferir melhor a distribuição das responsabilidades pelos diferentes intervenientes, os autores do relatório propóem uma representação numérica em que atribuem o valor 100 quando um determinado interveniente detém a responsabilidade exclusiva e, no outro extremo, o valor 0 quando náo detém nenhuma responsabilidade. Os valores intermédios significam que a responsabilidade é partilhada. O Quadro 1 resume a distribuição de responsabilidades (no conjunto de países que responderam ao inquérito) por cinco categorias de atores: os diretores, os professores, os conselhos de direção das escolas, as autoridades locais/regionais e as autoridades nacionais.

O relatório que temos estado a seguir salienta, contudo, que existe uma grande variedade de situaçóes, relativamente à autonomia da escola, entre os diferentes países da OCDE estudados (foram analisados 32 sistemas de educaçáo). Em média, os estabelecimentos que se situam em meios mais desenvolvidos economicamente, bem como as escolas do meio urbano, beneficiam-se de mais autonomia. Contudo, a correlação positiva entre a autonomia da escola e os resultados escolares nem sempre é evidente. Como referem Weidmann e Farmer, citados no relatório (OCDE, 2017, p. 129), os estudos mostram que só em certa medida o aumento da autonomia melhora os resultados escolares e isso só em alguns países. E mais à frente acrescentam:

Aliás, vários estudos mostram que para tirar plenamente partido da autonomia escolar, os sistemas de educação têm necessidade

\section{Quadro 1}

Distribuição das responsabilidades pelos atores.

\begin{tabular}{l|c|c|c|c|c}
\hline Responsabilidades & Diretores & Professores & $\begin{array}{c}\text { Conselhos } \\
\text { de direçáo }\end{array}$ & $\begin{array}{c}\text { Autoridades } \\
\text { locais/ } \\
\text { regionais }\end{array}$ & $\begin{array}{c}\text { Autoridades } \\
\text { nacionais }\end{array}$ \\
\hline Recursos & $39 \%$ & $3 \%$ & $12 \%$ & $23 \%$ & $23 \%$ \\
\hline Programas escolares & $22 \%$ & $44 \%$ & $8 \%$ & n.d. & n.d. \\
\hline Disciplina dos alunos & $39 \%$ & $29 \%$ & $22 \%$ & n.d. & n.d. \\
\hline $\begin{array}{l}\text { Políticas de avaliaçäo } \\
\text { dos alunos }\end{array}$ & $32 \%$ & $36 \%$ & n.d. & n.d. & n.d. \\
\hline $\begin{array}{l}\text { Políticas de admissão } \\
\text { dos alunos }\end{array}$ & $61 \%$ & n.d. & n.d. & $14 \%$ & $7 \%$ \\
\hline
\end{tabular}


de disporem de sistemas de responsabilização eficazes, a fim de desencorajar qualquer comportamento oportunista da parte do pessoal, bem como disporem de pessoal docente altamente qualificado para elaborarem avaliaçóes internas, assim como programas escolares rigorosos (OCDE, 2017, p. 129).

Essa ausência de "automatismo", na ligação entre mais autonomia e melhores resultados, faz com que a atenção seja posta mais nas caraterísticas da governança do que nos seus protagonistas.

Como o Quadro 2 mostra, existem as situaçóes mais variadas entre os diferentes países da OCDE, no que se refere ao tipo de governança e seus mecanismos.

Como resulta da análise efetuada

o grau de descentralização da tomada de decisão e a maior complexidade do processo de elaboraçáo das políticas ocupam doravante um lugar central entre as problemáticas ligadas à governança. Em vários países, o aumento da descentralização traduziu-se numa transferência de competências para as autoridades regionais e locais, enquanto o papel das escolas e dos ministérios da educação passou a ser de orientação e acompanhamento. [...] Quanto aos países mais centralizados é necessário conceder uma maior autonomia para que se dê uma melhor adaptaçáo às necessidades locais e para garantir uma boa

\section{Quadro 2}

Tipos de governança entre os países da Organização para a Cooperação e Desenvolvimento Económico.

\begin{tabular}{|c|c|c|c|c|}
\hline $\begin{array}{l}\text { Governança } \\
\text { central }\end{array}$ & $\begin{array}{l}\text { Governança } \\
\text { central e local }\end{array}$ & $\begin{array}{c}\text { Governança } \\
\text { central e escolas }\end{array}$ & $\begin{array}{c}\text { Governança } \\
\text { central em } \\
\text { concertaçáo com } \\
\text { as autoridades } \\
\text { regionais }\end{array}$ & $\begin{array}{c}\text { Governança } \\
\text { descentralizada }\end{array}$ \\
\hline $\begin{array}{l}\text { Áustria } \\
\text { França } \\
\text { Grécia } \\
\text { Hungria } \\
\text { Israel } \\
\text { Itália } \\
\text { Luxemburgo } \\
\text { Portugal } \\
\text { República Checa } \\
\text { Turquia }\end{array}$ & $\begin{array}{l}\text { Chile } \\
\text { Coreia do Sul } \\
\text { Dinamarca } \\
\text { Estónia } \\
\text { Finlândia } \\
\text { Islândia } \\
\text { Japão } \\
\text { Noruega } \\
\text { Polônia } \\
\text { Eslováquia } \\
\text { Eslovênia } \\
\text { Suécia }\end{array}$ & $\begin{array}{c}\text { Irlanda } \\
\text { Nova Zelândia } \\
\text { Países Baixos }\end{array}$ & $\begin{array}{l}\text { Espanha } \\
\text { México }\end{array}$ & $\begin{array}{c}\text { Alemanha } \\
\text { Áustria } \\
\text { Bélgica } \\
\text { Canadá } \\
\text { Estados Unidos } \\
\text { Reino Unido } \\
\text { Suíça }\end{array}$ \\
\hline
\end{tabular}

Fonte: $O C D E(2015, p .123)$. 
coordenação entre os decisores locais, regionais e nacionais. Paralelamente, numa altura em que a responsabilidade em relaçáo aos resultados da educação aumenta, as instituiçóes nacionais devem encontrar a estratégia mais adaptada para guiar as políticas educativas em ambientes complexos ou descentralizado (OCDE, 2015, p. 125).

A deslocação de poderes e de recursos entre os diferentes níveis de administração a que vimos assistindo um pouco por todo o mundo, para ser eficaz, tem de encontrar um equilíbrio entre o escaláo nacional e o escaláo regional e local. Como é referido em OCDE (2015, p. 120-121), os países com melhores performances têm objetivos claros para o seu sistema educativo, dispóem de instituiçóes preparadas para os atingir, com implicação das diferentes partes em presença e com um justo equilíbrio entre o governo central e o governo local. Os recursos financeiros, materiais e humanos devem ser adequados aos objetivos, garantido a coerência entre as estratégias de governança e o financiamento, para melhorar o rendimento do sistema educativo.

Esse equilíbrio entre os diferentes de administração é um dos fatores mais valorizados na definição de políticas que visam à melhoria dos sistemas educativos. Como a Figura 1 ilustra, o equilíbrio de poderes deve ser procurado entre o Estado (central), o município e a escola.

No primeiro caso, o Estado, por meio da centralização, define o modo de regulação política, estabelece a garantia de equidade e define o controlo de adequação e de qualidade.

\section{Figura 1}

Equilíbrio de poderes entre o Estado, o município e a escola.

\section{ESTADO}

Centralizaçáo

Regulação política

\section{MUNICÍPIO}

Descentralização

Administração e financiamento

\section{ESCOLA}

Autonomia

Pedagogia

Fonte: elaborado pelo autor. 
No segundo caso, o município, por intermédio da descentralização, procede à gestão administrativa e financeira, com base num "bolo" financiado pelo Estado, eventualmente reforçado por outras fontes.

No terceiro caso, a escola, pela autonomia, estabelece a definição e a aplicação dos procedimentos pedagógicos específicos num quadro delineado pelo Estado.

Esse equilíbrio de poderes deve realizar-se no quadro de uma multirregulação que inclui igualmente a regulação transnacional e que pode afetar de maneira distinta os diferentes níveis de administração no interior de cada país, como veremos a seguir.

\section{A multirregulação}

As políticas educativas foram influenciadas, desde sempre, por decisóes tomadas em diferentes níveis político-administrativos que costumamos identificar como transnacional, nacional e local, distinguindo, neste caso, os municípios (e freguesias) por um lado e as escolas por outro.

A variação do poder de influência de cada um desses níveis, em cada momento, determina as características mais peculiares da administração educativa.

Por isso, quando analisamos retrospetivamente a política educativa levada a cabo no território nacional não basta ter em conta as normas oriundas do ministério (nível nacional), mas igualmente o modo como elas incorporam abordagens de instâncias (países, agências ou investigadores) internacionais (nível transnacional), ou estão sujeitas a derivas locais, resultantes do poder formal ou informal dos municípios (nível municipal) e das escolas (nível escola).

A história da educação feita pelo diário da república ou pelos discursos oficiais é, como sabemos, um embuste e não tem em conta o efeito que as decisões tomam em cada ação concreta e o modo particular como afetam, em cada situação, os diversos atores educativos.

Por isso, no presente artigo, e como é mostrado na Figura 2, para cada um dos níveis atrás mencionados (transnacional, nacional, municipal, escola), irei selecionar uma política que seja paradigmática da influência que pode ser exercida nesse nível sobre o conjunto do sistema educativo. Depois de descrita sumariamente a política e analisados os seus efeitos principais, iremos ver como interagem as diferentes políticas e como podem, por essa razão, variar, localmente e no tempo, os seus efeitos.

No âmbito transnacional irei referir-me ao PISA, um estudo internacional que se iniciou em 2000, é feito de 3 em 3 anos pela OCDE e avalia a literacia dos alunos de 15 anos de idade em Ciências, Leitura e Matemática.

No âmbito nacional (Portugal) irei referir-me à política de utilização de plataformas eletrónicas pelo ministério da educação para registo e/ou operaciona- 
lização das mais diversas operações feitas pelas escolas quer no domínio administrativo, quer pedagógico, quer de avaliação.

No âmbito municipal vou referir-me às recentes medidas de descentralização propostas pelo governo português e que previstas, numa primeira fase, para serem aprovadas pela Assembleia da República antes do verão de 2017, foram objeto de um acordo entre os dois principais partidos portugueses (Partido Socialista e Partido Social-democrata) e aprovadas na generalidade na Assembleia da República, em julho de 2018.

Finalmente, no âmbito das escolas irei referir-me ao projeto de gestão flexível do currículo que, depois de ter estado em experiência, vai ser generalizado, no ano letivo de 2018-2019, ao conjunto das unidades orgânicas de educação públicas e privadas existentes em Portugal.

Como se pode ver, cada um dos exemplos envolve políticas que afetam, sobretudo, o nível para que são formuladas, mas têm um efeito abrangente sobre os outros níveis. É essa transversalidade que estabelece o equilíbrio de poderes entre o Estado, o município e a escola (atrás referida) e que será analisada no final deste artigo.

\section{A regulação transnacional: Programme for International Student Assessment}

A regulação transnacional não se faz diretamente e por um processo impositivo sobre os decisores, mas de maneira mais difusa por meio de normas, discursos e instrumentos que são produzidos e circulam nos fóruns de decisão e

\section{Figura 2}

Exemplo de diferentes políticas educativas por níveis de decisão, em Portugal.

Transnacional

PISA

Municipal

Propostas de descentralização

\section{Escola}

Projeto de gestáo flexível do currículo

\footnotetext{
Nacional

Plataformas eletrónicas

Fonte: elaborado pelo autor.
} 
consulta internacionais, no domínio da educação, e que são tomados, pelos políticos, funcionários ou especialistas nacionais, como obrigação ou legitimação, para adotarem ou proporem decisóes ao nível do funcionamento do sistema educativo (BARROSO, 2006a).

As agências transnacionais não atuam por meio de um poder soberano (por falta de fundamento e legitimidade democrática), mas sim por programas técnicos que sugerem (impóem) diagnósticos, metodologias, práticas, soluçôes (muitas vezes de maneira uniforme) que acabam por constituir uma espécie de "pronto-a-vestir" a que recorrem os especialistas dos diferentes países sempre que são solicitados (pelas autoridades ou opinião pública nacionais) a pronunciarem-se sobre os mais diversos problemas ou a apresentarem soluçóes.

Verificam-se, hoje em dia, uma naturalização desses processos (já não são vistos como estranhos nem desajustados às especificidades nacionais) e um aumento significativo das instâncias produtoras de conhecimento especializado e de uma grande intensidade e facilidade de difusão (sobretudo por meio pelas redes informáticas) de estudos, práticas, projetos, políticas.

A comparabilidade torna-se um instrumento de persuasão política e um critério para a formulação de juízos (de qualidade, eficácia etc.).

Existem vários exemplos de políticas educativas que resultam desse tipo de regulação e que se traduzem na adoção de medidas e de procedimentos semelhantes em vários países no que se refere à descentralização, à privatização da oferta educativa, à gestão centrada nas escolas, aos testes estandardizados, à avaliação dos professores e das escolas, etc. Mas o caso atual mais significativo desta regulação transnacional é o já referido PISA.

Luís Miguel Carvalho (professor do Instituto de Educação da Universidade de Lisboa), autor que em Portugal mais tem escrito sobre uma leitura crítica do PISA enquanto instrumento de regulação transnacional (e a que já fizemos referência na Introdução do presente artigo), mostra como o programa é utilizado nos espaços nacionais por diferentes atores na investigação, na política, na administração, na comunicação social, etc., com diferentes finalidades:

Para elaborar análises de políticas em curso; para justificar questóes específicas de agenda política; como fonte para realização de estudos sobre as "realidades nacionais"; ou para construir (ou desenvolver) instrumentos de regulação autóctones (designadamente no âmbito das políticas de prestação de contas e/ou de garantia de qualidade) (CARVALHO, 2013, p. 70).

Como Carvalho (2011, p. 164) refere:

O PISA é alimentado por e sustenta um conjunto de preceitos sobre os processos de regulação transnacional. Destacamos três, 
que nos parecem centrais. (1) O primado de um modelo racional e "baseado em evidência" para a coordenação e controlo das acçóes no sector da educaçáo (contrastando com uma coordenação baseada nas opinióes e/ou na ideologia). [...] (2) A "livre aquiescência” dos políticos — e sua adesão, envolvimento e apoio (material e simbólico) — à "mútua vigilância" como uma apropriada e eficaz prática de administração do social. (3) A avaliaçáo sistemática do desempenho dos alunos em certos "domínios e competências de literacia" como um recurso útil e confiável para a pilotagem dos sistemas educativos.

Por sua vez, Estela Costa (professora no mesmo Instituto de Educação) deixou claro na sua tese de doutoramento (COSTA, 2011) o modo como o PISA é elaborado pela OCDE e utilizado em Portugal pelas diversas entidades. As conclusóes do seu trabalho mostram claramente o papel fundamental do PISA na regulação transnacional e sua influência nas políticas nacionais: o programa coloniza diferentes universos do conhecimento e da sociedade e é ajustado pelos diferentes contextos e atores; o PISA instaura uma atmosfera de debate e reflexáo, concorrendo para a tecnicização e despolitização da ação pública; o conhecimento "dirige-se" para os políticos e os políticos "dirigem-se" para o conhecimento; as relações entre os atores envolvidos no PISA são multidirecionais e assimétricas; a imagem credível é uma construção da OCDE, sendo a atribuição de credibilidade uma construção da ação pública; documentos e reuniôes fazem a interface entre os diferentes espaços e atores.

Como Costa (2011, p. 290) afirma, ainda, na sua tese:

Neste processo, que envolve momentos de produção, de recepção e de troca de conhecimento, os documentos e os eventos emergem como cruciais, enquanto mecanismos de coordenaçáo das acçóes, permitindo fixar os actores ao Programa, com base em relaçóes de reciprocidade e de influência mútua. E, deste modo, a regulação dá-se pelo conhecimento incorporado no PISA, mas também na perspectiva do local onde esse conhecimento é produzido e do modo como é mobilizado, partindo de um conjunto de processos sociais de construção, circulaçáo e de tradução que ocorrem entre os diferentes níveis, e que lhe conferem uma natureza multidimensional.

Desse modo, o governo da educação "pela comparação" e "pelos números" torna-se um dos casos mais flagrantes dos efeitos dessa regulação transnacional por meio do PISA:

Para quem dirige o Programa, o que mais importa é que este seja reconhecido como ponto de passagem obrigatório para um debate e uma decisão política centrados em evidências científicas - criando "novos" problemas e disponibilizando novas in- 
formações "baseadas em evidências" — e, não tanto, ser uma instância que resolve problemas (ver Carvalho, 2009). Os surveys e os relatórios PISA são parte fundamental da exibição - pela OCDE — de uma capacidade constante de produção de inovação nos discursos políticos nacionais, de introdução de rupturas com os estereótipos da acção pública e de diferenciação face às ideias políticas nacionais (CARVALHO, 2009, p. 1029).

Contudo, importa salientar que a incorporação nas políticas nacionais dessas orientaçóes internacionais é, muitas vezes, unicamente discursiva e serve, sobretudo, para sossegar a opinião pública como garantia de racionalidade. Além disso, a transferência de conhecimentos, exemplos e práticas, de um país para outro, ou das agências internacionais para os diferentes países, não é um processo linear e automático. Esse processo é influenciado, sobretudo, pelo contexto histórico e político de cada país e condiciona as escolhas que são feitas.

\section{A regulação nacional: plataformas eletrónicas}

Como dizia em Barroso (2006a), a regulação nacional consiste no modo como as autoridades públicas (neste caso, o Estado e a sua administração) exercem a coordenação, o controlo e a influência sobre o sistema educativo orientando por meio de normas, injunçóes e constrangimentos o contexto da ação dos diferentes atores sociais e seus resultados.

Hoje, uma das maneiras mais comuns de orientar o contexto da ação dos diferentes atores sociais e os seus resultados é por intermédio do que se costuma chamar de instrumentos de regulação, entendidos como um dispositivo, ao mesmo tempo, técnico e social pelo qual a ação coletiva é estruturada com o fim de resolver um problema de natureza pública (SALAMON, 2002; LASCOUMES \& LE GALÈS, 2004).

Quer se trate de instrumentos legislativos, económicos, informativos, comunicacionais, de gestão ou outros, esses dispositivos configuram sempre, para além dos seus efeitos próprios, uma determinada conceção da ação pública (do seu sentido, do seu quadro cognitivo e normativo) e um modo específico de materializar e operacionalizar a ação governamental. "Cada instrumento é, por isso, uma forma condensada de saber sobre o poder social e as formas de o exercer" (LASCOUMES \& LE GALÈS, 2004, p. 29).

$\mathrm{Na}$ educação, grande parte desses instrumentos é baseada em conhecimentos produzidos especificamente para exercerem um efeito de regulação, como sejam, por exemplo, os dispositivos de avaliação, os referenciais de competências, os contratos de autonomia, as metas de aprendizagem, as "boas práticas", as "plataformas eletrónicas" etc. Esses instrumentos estão associados ao que Williamson (2016) chama de "digital education governance" (governo digital da educação). 
Segundo esse autor, o governo da educação é fortemente condicionado pelo "objetivo de quantificação de toda a espécie de comportamentos humanos e sociais" (WILLIAMSON, 2016, p. 124). Isso traduz-se na construção e alimentação sistemática de grandes bases de dados, com recurso às tecnologias digitais e ao que Williamson (2016, p. 124) chama de "instrumentos de política em tempo real".

É o que acontece nas nossas escolas, onde os professores e os diretores gastam cada vez mais tempo a alimentar as mais diversas plataformas informáticas de recolha e visualização de dados on-line, no domínio da avaliação, da gestão de recursos, da organização de horários etc.

Essa "regulação pelos instrumentos" permite, assim, um controlo indireto e, muitas vezes, a distância das políticas educativas, sendo responsável pelo fortalecimento de tendências burocráticas ou neoburocráticas na administração.

Como afirma Meira (2017), na sua importante tese de doutoramento sobre o uso, em Portugal, de diversas plataformas eletrónicas pela administraçáo escolar e sua influência determinante na preservação da burocracia (ou neoburocracia) educacional:

Foi apurado que os meios electrónicos favorecem a importância dos actos de microgestão quotidiana decorrente dos imperativos de traduzir electronicamente leis e procedimentos, incorporando nas funcionalidades das plataformas electrónicas intervençôes normativas imperceptíveis através das quais a administração educativa expande as suas competências conformadoras da lei e condiciona a operacionalidade e viabilidade das decisóes políticas e as dos actores da periferia (MEIRA, 2017, p. 395).

A utilização de plataformas eletrónicas cria uma situação de tripla dependência das escolas em relação à administração: por um lado, a vida escolar (sobretudo na sua dimensão mais administrativa) é formatada de modo a poder ser controlada pelas plataformas eletrónicas; por outro, mais do que os dados que são disponibilizados para administração é a possibilidade que esta tem de os consultar que conta; finalmente, a grande quantidade de plataformas existente e a exigência de as carregar e manter atualizadas condicionam o trabalho do gestor escolar e do seu staff.

As plataformas eletrónicas inserem-se, assim, numa estratégia de racionalização da administração educativa, "favorecendo a despersonalização e a indiferença de tipo mecânico às singularidades pessoais e organizacionais" (MEIRA, 2017, p. 394).

Em síntese e como o autor afirma no resumo das conclusóes do seu estudo:

As plataformas electrónicas proporcionam à Administração a possibilidade de novas formas de controlo, a aceleraçáo das tare- 
fas administrativas, o aumento exponencial das capacidades de cálculo e o exagero do registo minucioso, automático e retrospectivo. A investigação veio comprovar que na administração por via electrónica assumem especial importância os pequenos actos de gestáo baseados nos conhecimentos especializados de carácter tecnológico que proporcionam à cúpula da burocracia electrónica o poder de condicionar esferas cada vez mais relevantes do funcionamento quotidiano do sistema organizacional (MEIRA, 2017, p. VIII).

\section{A regulação municipal: a descentralização}

A regulação municipal foi objeto de uma tentativa de regulamentação a partir da discussão de uma proposta de lei, aprovada pelo Conselho de Ministros em fevereiro de 2017, na qual era definido o quadro de transferência de competências para as autarquias locais e entidades intermunicipais.

Essa legislação tinha sido antecedida por uma experiência aprovada pelo XIX governo, iniciada em 2015, Aproximar Educação, abrangendo 14 autarquias (inicialmente 15) que celebraram contratos interadministrativos num processo de delegação de competências.

A discussão pública da proposta de lei que decorreu, entretanto, deverá dar lugar à discussão e à votação na Assembleia da República de um diploma sobre a matéria na sessão legislativa agora iniciada.

Segundo essa proposta ${ }^{6}$ :

Existe um reforço das competências das autarquias que passam a assumir todas as funçóes de recrutamento e gestão do pessoal não docente (algumas das quais eram partilhadas anteriormente com as escolas), a gestão exclusiva dos refeitórios e das refeições escolares, o apoio a beneficiários da ação social escolar, a participação na organização da segurança escolar e a construção, o planeamento, a gestão e o investimento em todas as escolas do ensino não superior incluindo as escolas profissionais (PRESIDÊNCIA DO CONSELHO DE MINISTROS, 2017).

A questão global colocada nos diversos quadrantes é saber como é garantida, na Lei das Finanças Locais, a transferência de verbas para as autarquias fazerem perante as novas competências. Questão que o governo diz que só poderá responder quando estiverem estabilizadas as competências a transferir depois do processo de consulta que está a decorrer.

Regista-se ainda o receio, manifestado pelos responsáveis de várias associaçóes de dirigentes escolares, de a escola perder as margens de autonomia de que dispóe, o que se traduz na manutenção da crítica a uma eventual "municipa- 
lização" oriunda da Federação Nacional de Professores (FENPROF) e da falta de fundamentação global da proposta por parte do Conselho Económico e Social.

Entretanto, em 22 de junho de 2017, o Conselho das Escolas ${ }^{7}$ divulgou o seu parecer aprovado por unanimidade dos membros presentes (Parecer no 2/2017, Projeto de Decreto-Lei sobre Descentralização-educação) ${ }^{8}$.

Embora considere que "o atual sistema educativo está excessivamente centralizado e dependente de uma administração educativa volumosa" (p. 1), o Conselho das Escolas considera "erráticas" as várias medidas de "combate ao centralismo" tomadas pelos diversos governos e manifesta uma oposição global à Proposta de Lei posta em discussão. A argumentação utilizada põe em evidência o que considera ser o "esvaziamento da autonomia das escolas", elencando um conjunto de competências (p. 6-7) que "estando hoje na esfera das Escolas e dos seus órgãos de Administração e Gestão, passarão para a esfera das autarquias caso venha a ser implementado o modelo de descentralização em apreciação". Como é dito no parecer (p. 5):

"O processo de perda de competências das escolas para as autarquias poderá ser lento, mas será irreversível” principalmente nos seguintes domínios: "a autonomia das Escolas ficará acantonada, apenas, às áreas pedagógica e curricular"; "as instalaçóes e equipamentos serão geridos pelas escolas, apenas, durante o decorrer das atividades letivas"; "as escolas perderão fontes de receitas e as despesas serão assumidas pelas autarquias”.

Embora existam outros aspetos em que o Conselho das Escolas manifesta discordância com a proposta do governo (plano de transporte escolar, ação social escolar, pessoal não docente, conselho municipal de educação), o ponto central da oposição prende-se com os critérios da partilha de competências que são propostos (curricular e pedagógico para a escola; administrativo e financeiro para a autarquia) e com o receio de perda da dimensão institucional da escola.

Curiosamente, apesar de serem conhecidas as dissensóes entre o Conselho das Escolas e a FENPROF, e nunca no parecer ser referida a ameaça da "municipalização", verifica-se uma grande semelhança nos argumentos invocados, em particular, no que se refere ao excessivo poder das autarquias. O parecer do Conselho das Escolas levanta essa questão, principalmente no ponto IX, intitulado "escola instituiçẫo ou escola serviço", quando lamenta que não existam na proposta referências às competências e aos meios à disposiçáo das escolas, como se pode ver particularmente no último ponto da conclusão (p. 14):

11. Os maiores problemas e os maiores perigos para a Escola pública e para a Educação, decorrentes deste processo de descentralização, advirão da circunstância de o mesmo favorecer o esvaziamento do caráter institucional das Escolas e abrir portas 
a que estas se transformem em meros serviços municipalizados, subordinados ao poder autárquico do momento e podendo ser utilizadas como peças do jogo político autárquico, em prejuízo da sua nobre missão.

Importa, por último, assinalar que entre fevereiro e junho de 2017 funcionou na Assembleia da República um grupo de trabalho da $11^{\text {a }}$ comissão para fazer o Acompanhamento das Transferências de Competências na Educação, coordenado pela deputada Susana Amador (Partido Socialista). Esse Grupo de Trabalho realizou, entre 16 de fevereiro de 2017 e 14 de julho de 2917, 14 audiçóes sobre a proposta de lei elaborada pelo governo, tendo ouvido, entre outros, membros de governos, presidente do conselho de escola, associação nacional de municípios portugueses e associação nacional de freguesias, confederação nacional das associaçóes de pais, vários sindicatos de professores e de inspetores da educação? .

Entretanto, em abril de 2018, o governo (do Partido Socialista) e o Partido Social-democrata (principal partido da oposição) celebraram um acordo para a aprovação da "lei-quadro da descentralização de competências do estado central para as autarquias locais e entidades intermunicipais" que entrara no Parlamento em março de 2017 (e a que temos estado a fazer referência). Essa legislação mereceu também uma deliberação favorável (na generalidade) das associaçóes representativas dos municípios e das freguesias e foi aprovada pelo Parlamento. Apesar de não ter sido possível concluir toda a legislação prevista na presente legislatura (que terminou em julho do corrente ano), prevê-se concluir o processo de modo a que seja tido em conta no orçamento do próximo ano (2019), nomeadamente o Fundo para a Descentralização, com valor calculado em 889,7 milhóes de euros.

Em 2 de agosto de 2018, o presidente da república aprovou a Lei-quadro da Descentralização e a Lei das Finanças Locais, embora tenha posto algumas reservas (nomeadamente por considerar a sua formulação demasiado geral), declarando esperar que os vários diplomas complementares venham a esclarecer as suas dúvidas. Conforme declaraçōes que a imprensa refere, o presidente exprimiu a sua preocupação com o não agravamento das desigualdades entre autarquias locais; a exequibilidade do aprovado sem riscos de indefinição, com incidência mediata no rigor das finanças públicas; o não afastamento excessivo e irreversível do Estado de áreas específicas em que seja essencial o seu papel, sobretudo olhando à escala exigida para o sucesso de intervençóes públicas.

Nesse momento, no que se refere à educação, está previsto que as autarquias venham a assumir diversas responsabilidades, abrangendo 43.262 funcionários não docentes, 996 agrupamentos e escolas, em 3.552 edifícios. De um modo geral, essas responsabilidades referem-se ao planeamento, à gestão e à realização de investimentos nos estabelecimentos públicos de educaçáa e de ensino integrados na rede pública do $2^{\circ}$ e $3^{\circ}$ ciclos do ensino básico, secundário, incluindo o 
profissional. Além disso, as autarquias asseguram para todo o ensino não superior e a educação pré-escolar o transporte escolar, as refeiçóes escolares e a gestão dos refeitórios, devendo, ainda, apoiar beneficiários da ação social escolar e recrutar e gerir o pessoal não docente.

$\mathrm{O}$ processo de transferência de competências que se desenrola faseadamente até as próximas eleiçóes autárquicas (em 2021) vai ser acompanhado por uma comissão aprovada pelo parlamento e constituída por representantes dos grupos parlamentares, do governo, da Associação Nacional de Municípios e da Associação Nacional de Freguesias.

\section{Regulação na escola: projeto flexível do currículo}

Finalmente, ao nivel da escola irei referir-me à experiência que se iniciou no ano letivo de 2017-2018, em 235 agrupamentos de escolas ou escolas náo agrupadas, públicas e privadas, incluindo escolas profissionais e quatro escolas portuguesas no estrangeiro. De acordo com o próprio ministério (Direção-Geral de Educação):

[O projeto de flexibilização curricular] visa a promoção de melhores aprendizagens indutoras do desenvolvimento de competências de nível mais elevado, assumindo a centralidade das escolas, dos seus alunos e professores, e permitindo a gestão do currículo de forma flexível e contextualizada, reconhecendo que o exercício efetivo de autonomia em educação só é plenamente garantido se o objeto dessa autonomia for o currículo (PORTUGAL, 2018).

As escolas e os agrupamentos são obrigados a respeitar as "aprendizagens essenciais" que, construídas a partir dos programas em vigor, elencam os conhecimentos, as capacidades e as atitudes a desenvolver por todos os alunos, de acordo com o "perfil dos alunos à saída da escolaridade obrigatória".

A flexibilização curricular tem essencialmente os seguintes objetivos: consolidar aprendizagens de forma efetiva; desenvolver competências que requerem mais tempo (realização de trabalhos que envolvem pesquisa, análise, debate e reflexão); permitir efetiva diferenciação pedagógica na sala de aula. Para Filinto Lima, presidente da Associação Nacional dos Diretores de Agrupamentos e Escolas Públicas, trata-se de um voto de confiança numa maior autonomia das escolas na gestão curricular, já que, atualmente, as cerca de 300 escolas com contrato "apenas têm autonomia para cumprir as decisôes do ministério" (DIÁRIO DE NOTÍCIAS, 2017).

De acordo com o próprio ministério, não há revogação de documentos em vigor, nem a consequente adoção de novos manuais. 
As "aprendizagens essenciais" são o Denominador Curricular Comum para todos os alunos, mas não esgotam o que um aluno deve fazer ao longo do ano letivo.

Não são os mínimos a atingir para a aprovação de um aluno, são a base comum de referência. Permitem libertar espaço curricular para que, em cada escola, seja possível promover trabalho articulado entre as aprendizagens essenciais e as outras aprendizagens previstas nos demais documentos curriculares, com aprofundamento de temas, explorações interdisciplinares diversificadas, mobilização de componentes locais do currículo, entre outras opçōes, no âmbito dos domínios de autonomia curricular. A aprovação do aluno dependerá sempre das aprendizagens realizadas, decorrentes da articulação entre a base comum de referência e o aprofundamento de outros conteúdos e temas, articulação que é orientada pelas áreas das competências inscritas no perfil do aluno.

As escolas deverão elaborar a construção do seu próprio currículo levando em conta as aprendizagens essenciais e o perfil do aluno, tendo o ministério disponibilizado um documento auxiliar elaborado por três especialistas (Maria do Céu Roldão, Helena Peralta e Isabel P. Martins) intitulado "Currículo do ensino básico e do ensino secundário - para a construção de aprendizagens essenciais baseadas no perfil dos alunos" (agosto de 2017).

De acordo com esse documento:

Estes passos iniciais de um currículo que forme cidadãos para as décadas próximas do século XXI implicarão, a prazo, uma reformulaçáo global do currículo nestes moldes, integrando ou reconvertendo gradualmente os múltiplos e sobrepostos referentes que se têm acumulado, dificultando uma melhor racionalização do trabalho dos professores e escolas e a mais efetiva aprendizagem de todos os alunos. Esta transformação no plano curricular assume-se como gradual e participada, existindo o cuidado de manter os referentes curriculares existentes enquanto se processa uma reconstrução curricular a prazo (ROLDÃO et al., 2017, p. 4).

No próximo ano letivo (2018-2019) está previsto generalizar a todos os agrupamentos e escolas isoladas essa experiência de flexibilização curricular.

\section{A transversalidade das regulações}

Os exemplos utilizados mostram como um dispositivo definido para um determinado nível de regulação pode influenciar o conjunto do sistema educativo: o PISA no âmbito internacional, as plataformas eletrónicas no âmbito nacional, a política de descentralização no âmbito dos municípios e a gestáo flexível do currículo, no âmbito das escolas. Contudo, apesar desse eventual efeito conjunto, 
cada uma das medidas exemplifica bem a especificidade da regulaçáo exercida nos diferentes níveis e a complementaridade existente entre elas.

Os exemplos utilizados servem para ilustrar um modelo de funcionamento do sistema educativo com diferentes níveis de centralidade que combina regulaçôes de controlo e regulaçóes autónomas, cujo equilíbrio determinará mecanismos de regulação compósita.

Como a Figura 3 ilustra, exerce-se uma regulaçáo que visa o "controlo de resultados" no âmbito transnacional, o "controlo de procedimentos" no âmbito nacional, a "autonomia administrativa" no âmbito municipal e a "autonomia pedagógica" no âmbito da escola.

O efeito conjunto dessas regulações dará lugar a uma multirregulação cujo efeito se constrói de maneira compósita.

Contudo, se isso é assim no âmbito de um modelo teórico de regulação, na prática, as coisas passam-se de modo mais variável, em função da correlação de forças que se estabelece entre os vários níveis de regulação.

Falando da situação portuguesa, podemos dizer que o Ministério da Educação, no âmbito nacional, mantém a primazia de facto, embora procedimentalmente tenha de conceder mais poder aos outros níveis.

A situação existente configura um misto de dimensões emergentes de regulação pós-burocrática e de regulação neoburocrática que se fazem sentir sobre formas tradicionais de regulação burocrática e regulação burocrático-profissional.

No primeiro caso, a regulação pós-burocrática caracteriza-se, sobretudo, pelo facto de não se basear, como no modelo burocrático, na legitimidade da ra-

\section{Figura 3}

Transversalidade das regulaçôes e multirregulação.

Controlo de resultados

\section{Municipal \\ Propostas de descentralização}
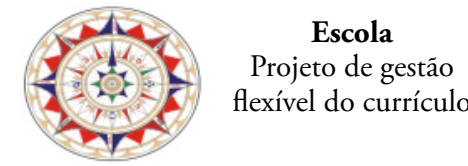

Nacional

Plataformas eletrónicas flexível do currículo

Controlo dos procedimentos

Fonte: elaborado pelo autor. 
cionalidade e da lei, consideradas, simultaneamente, como formas de coordenação e fonte de valores. A racionalidade continua a ser valorizada, mas ela é reduzida, sobretudo, à racionalidade instrumental. O controlo a priori, pelas normas, é substituído pelo controlo a posteriori, pelos resultados (BARROSO, 2006a).

No segundo caso, na regulação neoburocrática a alteração das formas de governo é orientada para melhorar o funcionamento burocrático da administração, face ao aumento da complexidade e diversidade do sistema. Isso significa que é preciso mudar qualquer coisa (os aspetos morfológicos) para preservar a essência do poder e da autoridade do Estado e dos seus sistemas de controlo. Muitas vezes, as transformaçóes da gestão justificadas pelo "new public management" não passam de uma "modernização cosmética" da administração pública ao serviço dos mesmos fins e do mesmo modelo de funcionamento (BARROSO, 2006a).

Para finalizar, importa destacar que uma das principais conclusóes que se pode tirar sobre a transversalidade das regulaçóes consiste na coexistência de diferentes modalidades de regulação quer quanto ao nível onde se exerce (transnacional, nacional, municipal, escola), quer quanto às suas finalidades (controlo de resultados, controlo de procedimentos, autonomia administrativa autonomia pedagógica), quer quanto à sua forma (burocrática, pós-burocrática, neoburocrática). Isso significa que existe sempre uma tensão entre diferentes variedades e que a regulação é sempre compósita, com índices de preponderância diferente, em função das políticas e das dinâmicas existentes em cada situação e em cada momento.

Por isso, se queremos encontrar uma alternativa ao modo como tem sido gerida a educação em Portugal, e nos outros países em geral, devemos ser capazes de construir uma nova ordem educativa local, tendo em conta a pluralidade de atores institucionais, coletivos ou individuais, envolvidos nos processos educativos. Isso obriga a prática de uma regulaçâo compósita articulando diferentes modalidades, incidindo sobre diferentes campos e mobilizando diferentes atores, numa espécie de "geometria variável" ajustada à pluralidade de condições e de necessidades existentes.

\section{Notas}

1. Ver relatório final em: <https://cordis.europa.eu/docs/publications/1001/100123981-6_en.pdf>. Acesso em: 15 set. 2018.

2. Ver também Marois (2006), em que são apresentadas sínteses finais de todos os países participantes.

3. Consultar: <https://cordis.europa.eu/project/rcn/86459_en.html>. Acesso em: 15 set. 2018.

4. Merece particular destaque as pesquisas que Luís Miguel Carvalho desenvolveu sobre o PISA, na continuidade da investigaçáo realizada no Knowandpol e de que existe um dossiê publicado na revista Educação \& Sociedade no 136 (CARVALHO, 2016), entre outras publicações. 
5. O termo governança é utilizado no sentido que é dado pelo Dicionário da Lingua Portuguesa, da Porto Editora: "2. (Uniäo Europeia) forma de governar baseada no equilibrio entre o Estado, a sociedade civil e o mercado, ao nivel local, nacional e internacional (do francês antigo gouvernance, «idem»)".

6. Proposta de lei aprovada pelo Conselho de Ministros em fevereiro de 2017, em que era definido o quadro de transferência de competências para as autarquias locais e entidades intermunicipais.

7. Conselho representativo dos diretores das escolas.

8. Ver em: <http://www.cescolas.pt/wp-content/uploads/2017/06/Parecer_02_2017_Descentralizacao.pdf $>$. Acesso em: 15 set. 2018.

9. Os relatos das diversas reuniốes estáo disponíveis na internet, na página do parlamento, e a sua leitura ou visualização é muito interessante para perceber o que está em jogo (para os diversos intervenientes) nessa legislaçáo.

\section{Referências}

BARROSO, J. Organização e regulação dos ensinos básico e secundário, em Portugal: sentidos de uma evolução. Educação \& Sociedade, Campinas, v. 24, n. 82, p. 63-92, 2003. http://dx.doi.org/10.1590/S0101-73302003000100004

O Estado, a educação e a regulação das políticas públicas. Educação \& Sociedade, Campinas, v. 26, n. 92, p. 725-751, 2005. http://dx.doi.org/10.1590/S010173302005000300002

O Estado e a educação: a regulação transnacional, a regulação nacional e a regulação local. In: BARROSO, J. (Org.). A regulação das políticas públicas de educação: espaços, dinâmicas e actores. Lisboa: EDUCA e Unidade de I\&D em Ciências da Educação, 2006a. Disponível em: <http://hdl.handle.net/10451/5761>. Acesso em: 15 set. 2018.

A regulação das políticas públicas de educação: espaços, dinâmicas e actores. Lisboa: EDUCA e Unidade de I\&D em Ciências da Educação, 2006b. Disponível em: < $\underline{\text { http:// }}$ hdl.handle.net/10451/5761>. Acesso em: 15 set. 2018.

. A utilização do conhecimento em política: o caso da gestão escolar em Portugal. Educação \& Sociedade, Campinas, v. 30, n. 109, p. 987-1007, 2009. http://dx.doi. org/10.1590/S0101-73302009000400004

Autonomia, contratos e direção de escolas. In: MACHADO, J.; ALVES, J.M. (Coord.). Escola para Todos: Igualdade, Diversidade eAutonomia. Porto: Universidade Católica, 2014. p. 91-111. Disponível em: <http:/www.uceditora.ucp.pt/resources/Documentos/ UCEditora/PDF\%20Livros/EscolaParaTodos_e-Book.pdf>. Acesso em: 15 set. 2018.

. Autonomia das escolas: entre público e privado. In: PERONI, V.M.V. (Org.). Redefiniçôes das fronteiras entre o público e o privado: implicaçóes para a democratização da educação. Brasília: Líber Livro, 2013. p. 48-57.

. Centralização, descentralização, autonomia e controlo. A regulação vitruviana. In: LIMA, L.; SÁ, V. (Orgs.). O Governo das Escolas. Braga: Húmus, 2017. p. 23-40. 
. Descentralização, territorialização e regulação sociocomunitária da educação. Revista de Administração e Emprego Público, n. 4, p. 7-29, abr. 2018.

BARROSO, J.; AFONSO, N. (Orgs.). As politicas educativas em Portugal: mobilização de conhecimento e modos de regulação. Vila Nova de Gaia: Fundação Manuel Leão, 2011.

BARROSO, J.; VISEU, S. A emergência de um mercado educativo no planejamento da rede escolar: de uma regulação pela oferta a uma regulação pela procura. Educação \& Sociedade, Campinas, v. 24, n. 84, p. 897-921, 2003. http://dx.doi.org/10.1590/S0101$\underline{73302003000300008}$

CARVALHO, L.M. Governando a educação pelo espelho do perito: uma análise do PISA como instrumento de regulação. Educação \& Sociedade, Campinas, v. 30, n. 109, p. 1009-1036, 2009. http://dx.doi.org/10.1590/S0101-73302009000400005

. Mútua vigilância organizada. Educação: Temas e Problemas, v. 6, n. 12-13, p. 61-74, 2013.

. (Coord.). O espelho do perito. Inquéritos internacionais, conhecimento e política em educação - o caso do PISA. Vila Nova de Gaia: Fundação Manuel Leão, 2011.

. PISA, política e conhecimento em educação. Educação \& Sociedade, Campinas, v. 37, n. 136, p. 601-607, 2016. http://dx.doi.org/10.1590/ES0101-73302016168897

COSTA, E. O 'Programme for International Student Assessment' (PISA) como instrumento de regulação das políticas educativas. Tese (Doutoramento em Educação) - Instituto de Educação, Universidade de Lisboa, Lisboa, 2011. Disponível em: <http://hdl.handle. net/10451/3002>. Acesso em: 15 set. 2018.

COSTA, E.; AFONSO, N. Os instrumentos de regulação baseados no conhecimento: o caso do Programme for International Student Assessment (PISA). Educação \& Sociedade, Campinas, v. 30, n. 109, p. 1037-1055, 2009. http://dx.doi.org/10.1590/S0101-73302009000400006

DELVAUX, B. Qual é o papel do conhecimento na ação pública? Educação \& Sociedade, Campinas, v. 30, n. 109, p. 959-985, 2009. http://dx.doi.org/10.1590/S0101$\underline{73302009000400003}$

DIÁRIO DE NOTÍCIAS. Entrevista a Filinto Lima. 23 de março de 2017.

LASCOUMES, P. ; LE GALÈS, P. Gouverner par les instruments. Paris: Presses de Sciences Po, 2004.

MAROIS, C. École, régulation et marché. Une comparaison de six espaces scolaires locaux en Europe. Paris: PUF, 2006.

MEIRA, M. A Burocracia Electrónica: Um Estudo sobre as Plataformas Electrónicas na Administração Escolar. Tese (Doutorado) - Instituto de Educação, Universidade do Minho, Braga, 2017. Disponível em: <https://repositorium.sdum.uminho.pt/ bitstream/1822/50877/1/Manuel\%20do\%20Vale\%20Fernandes\%20Meira.pdf >. Acesso em: 15 set. 2018 .

ORGANIZAÇÃO PARA A COOPERAÇÃO E DESENVOLVIMENTO ECONÓMICO (OCDE). Perspectives des politiques de l'éducation 2015. Les réformes en marche. Paris: OCDE, 2015. 
Résultats du PISA 2015 (volume II): Politiques et pratiques pour des établissements performants. Paris: OCDE, 2017.

PORTUGAL. Direção-geral da Educação. Autonomia e flexibilidade curricular. Portugal: Direção-geral da Educação, 2018. Disponível em: <http://www.dge.mec.pt/autonomia-eflexibilidade-curricular>. Acesso em: 15 set. 2018.

PRESIDÊNCIA DO CONSELHO DE MINISTROS. Proposta de Lei 62/XIII. Estabelece o quadro de transferência de competências para as autarquias locais e para as entidades intermunicipais, concretizando os princípios da subsidiariedade, da descentralização administrativa e da autonomia do poder local. Lisboa: Assembleia da República, 2017.

ROLDÃO, M.C.; PERALTA, H.; MARTINS, I.P. Currículo do ensino básico e do ensino secundário - para a construção de aprendizagens essenciais baseadas no perfil dos alunos. Lisboa: República de Portugal, ago. 2017. Disponível em: <http://www.dge.mec.pt/ sites/default/files/Curriculo/Projeto Autonomia e Flexibilidade/ae documento enquadrador.pdf>. Acesso em: 15 set. 2018.

SALAMON, L. (Ed.). The Tools of Government. A guide to the new governance. Oxford: University Press, 2002.

WILLIAMSON, B. Digital education governance: data visualization, predictive analytics, and 'real-time' policy instruments. Journal of Education Policy, v. 31, n. 2, p. 123-141, 2016. http://dx.doi.org/10.1080/02680939.2015.1035758

Recebido em 17 de setembro de 2018.

Aceito em 24 de setembro de 2018. 